\title{
干旱与湿润区流域时变水热耦合参数的归因分析
}

\author{
赵香桂 ${ }^{1}$, 黄生志 ${ }^{1, *}$, 赵 静 ${ }^{1}$, 韩知明 ${ }^{1}$, 魏晓婷 ${ }^{1}$, 黄 强 $^{1}$, 邓铭江 ${ }^{1,2}$ \\ 1 西安理工大学 西北旱区生态水利国家重点实验室,西安 710048 \\ 2 新疆寒早区水资源与生态水利工程研究中心, 乌鲁木齐 830000
}

摘要:气候变化和下垫面条件的改变共同影响着流域的水热耦合状况,定量剖析其影响对研究变化环境下流域水量平衡和能量 分配具有重要意义。以往多数研究只做了定性分析,对不同影响因素的定量贡献研究甚少。基于此, 以干旱区无定河流域和湿 润区汉江上游为研究区域,在 Budyko 框架下,估算了干旱与湿润区流域的时变水热耦合参数,并通过逐步多元回归模型、敏感 性和贡献率分析, 定量归因了水热耦合控制参数的演变,并将干旱与湿润区流域做了对比分析。结果表明:干旱与湿润区流域 的水热耦合参数在 1970-2013 年间均呈显著上升趋势; 不同气候区水热耦合参数变化的主导因子不同,干旱区无定河参数对 降水和植被覆盖度 (NDVI) 具有较高的敏感性,且 NDVI 的变化主导着参数的变化(贡献率为 $89.5 \%$ ); 湿润区汉江上游参数的 变化对气温、有效灌溉面积 (EIA) 和 NDVI 更敏感,其中,EIA 主导着参数的变化(贡献率为 $83.1 \%$ ); 总体来说,下垫面的变化是 无定河和汉江上游水热状况改变的驱动因素。

关键词:变化环境;水热耦合;植被覆盖度 (NDVI);敏感性分析;Budyko 框架;归因分析

\section{Comparative analysis of the attribution of time-varying water-heat coupling parameters in arid and humid basin}

ZHAO Xianggui ${ }^{1}$, HUANG Shengzhi ${ }^{1, *}$, ZHAO Jing $^{1}$, HAN Zhiming $^{1}$, WEI Xiaoting ${ }^{1}$, HUANG Qiang ${ }^{1}$, DENG Mingjiang ${ }^{1,2}$

1 State Key Laboratory of Eco-hydraulics in Northwest Arid Region of China, Xi'an University of Technology, Xi'an 710048, China

2 Research Center for Water Resources and Ecological Water Conservancy Engineering in Cold and Arid Regions of Xinjiang, Urumqi 830000, China

\begin{abstract}
Under the background of global warming, the climate condition and underlying surface conditions of the Yellow River and the Yangtze River has changed significantly. Simultaneously, the intensification of human activities (e.g. urbanization, industrialization, grain for green and irrigation, etc.) has led to changes in underlying surface condition, which further changed the distribution of precipitation between evaporation, infiltration and runoff, thus affecting the hydrological cycle process. However, the change of climate change and underlying surface conditions jointly affect the watershed water-energy balance, and quantitative analysis their influence in different climatic regions is of great significance to the study of water balance and energy distribution of the basin under the changing environment. most of the previous studies only made qualitative analysis, and few studies focused on quantitative contributions. In addition, under the complex changing environment, the study of the changes of hydrological processes in different climatic regions and the influencing factors are helpful for the profound understanding of the change characteristics of hydrological processes in different climatic regions. Based on them, The Wuding River Basin in arid region and the upper Han River in humid region were selected as

基金项目:国家自然科学基金项目(51709221); 陕西省高校科协青年人才托举计划项目(20190413); 陕西省创新人才推进计划-青年科技新星项 目 (2019KJXX-051)

收稿日期: 2020-10-22; 网络出版日期:2021-08-04

*通讯作者 Corresponding author.E-mail: huangshengzhi7788@126.com
\end{abstract}


the study areas in the study. The time-varying Budyko parameter was estimated under the Budyko framework. In addition, the attribution of the evolution of the parameter was revealed quantitatively by the stepwise multiple regression model, sensitivity and contribution analysis. Moreover, a comparative analysis was made between the arid and humid regions. The results showed that the Budyko parameter increased significantly from 1970 to 2013 in the two selected areas with different driving factors. The dominant factors driving the variation of the parameter are different in diverse climatic regions. In the Wuding River basin, the parameter is highly sensitive to precipitation and vegetation coverage ( NDVI), and the variation of the NDVI dominates its variation (the contribution rate is $89.5 \%$ ). However, in the upper Han River, the variation of the parameter is more sensitive to temperature, effective irrigation area (EIA) and NDVI, and among which, the EIA dominates its variation (the contribution rate is 83.1\%). In general, the change of underlying surface is the driving factor for the change of water and energy conditions in the Wuding River and the upper Han River.

Key Words : changing environment; water-energy balance; NDVI; sensitivity analysis; Budyko framework ; attribution analysis

随着全球气候变暖,黄河和长江流域地区气候发生了明显变化; 同时, 两区域人类活动 (如城市化、工业 化、退耕还林还草和农田灌溉等) 也在不断加剧, 使得流域下垫面条件发生改变, 进而影响降水在蒸发、下渗 和径流之间的分配, 从而影响水循环过程 ${ }^{[1-3]}$ 。无定河流域是黄河中游的典型一级支流, 自 1999 年以来实施 的水土保持和退耕还林还草等生态修复工程实施以来。流域植被覆盖条件明显改善,但也造成径流量急剧减 少, 从而使得生态环境和经济发展之间供需水矛盾愈发突出 ${ }^{[4-6]}$ 。同样地, 地处长江流域的汉江上游地区经 济的快速发展及引水工程的逐年增多, 也加剧了径流的衰减 ${ }^{[3]}$, 水矛盾问题日益显著。因此, 在复杂的变化 环境下,研究不同气候区流域水文过程的变化并探究其影响因素,有助于深刻认识不同气候区水文过程的变 化特征。

气候和下垫面条件的变化是影响流域水文循环的主要因素, 定量分析两者对径流和流域水热耦合动态变 化的影响是当前水文研究的热点和难点。目前较为常用的研究方法主要是水文模型模拟和 Budyko 水热耦合 理论 ${ }^{[3,7]}$ 。水文模型虽然能有效模拟流域水文过程, 但对输人数据要求高, 模型的不确定性较大, 故模拟结果 存在较大误差 ${ }^{[8-9]}$ 。而 Budyko 水热耦合理论因包含表征流域下垫面特征的参数,使模型具有一定物理意义, 且计算过程相对简单, 被广泛应用于水文领域的研究中 ${ }^{[10-11]}$ 。Patterson 等 ${ }^{[12]}$ 应用 Budyko 理论评估了气候和 直接的人类活动对美国南大西洋径流量的影响; $\mathrm{Xu}$ 等 ${ }^{[13]}$ 基于 Budyko 理论对海河流域径流的减小进行了归 因分析; Huang 等 ${ }^{[14]}$ 使用 Budyko 假设和 SVM 模型量化了气候和人类活动对径流变化的贡献率; 杨大文等 ${ }^{[15]}$ 基于 Budyko 理论, 以黄河流域 38 个典型子流域为研究对象对径流变化进行了归因分析; 张丽梅等 ${ }^{[16]}$ 基于 Budyko 框架, 估算了渭河径流变化对各驱动因素的弹性系数,进而定量分解了气候变化和人类活动对径流变 化的贡献率; 上述基于 Budyko 框架的研究主要聚焦于径流的定量归因分析,侧重于水热平衡理论的应用,而 关于 Budyko 框架本身的研究甚少, 故本研究拟开展对 Budyko 框架中水热耦合参数 $n$ 的定量归因研究。此 外, 以往关于 Budyko 框架理论与应用的研究中, 表征下垫面特征的水热耦合参数均被视作恒定值, 即认为其 在多年尺度上保持不变。但流域下垫面条件往往存在年际或年内尺度上的变化,故基于恒定参数所模拟的流 域水热状况不能精准的反应流域的水文演变规律。因此,本文探究了变化环境下流域水热耦合参数 $n$ 的动态 变化规律, 并定量分析了气候变化和下垫面条件的改变对其动态变化的驱动机制。此外,干旱区和湿润区不 仅气候条件不同, 植被覆盖度和农田灌溉情况也大不相同, 以往开展的相应研究也未在不同气候区进行归因 对比分析。

综上所述,水热耦合状况对气候变化和下垫面条件改变的响应是一个较复杂的过程。鉴于此,本研究选 取气候类型差异显著且下垫面条件变化较大的两个流域——无定河和汉江上游为研究对象,估算干旱与湿润 区流域的时变水热耦合参数, 并通过逐步多元回归模型、敏感性和贡献率分析, 定量揭示水热耦合控制参数演 
变的归因,并将干旱与湿润区流域作对比分析,揭示不同气候区水文循环过程的联系与区别,研究结果可为深 人探究流域水文过程的演变、指导流域水资源合理开发利用和生态环境的保护提供科学依据。

\section{1 研究区域与数据}

\section{1 研究区概况}

无定河流域是黄河中游河口至龙门区间最大的支流,位于陕西省北部, 发源于定边县白于山,流经定边、 靖边、米脂、绥德等县, 于清涧县河口村汇人黄河。无定河全长 $491 \mathrm{~km}$, 流域面积 3.03 万 $\mathrm{km}^{2}$, 流域地理位置 处于 $37^{\circ} 02^{\prime}-39^{\circ} 00^{\prime} \mathrm{N}, 107^{\circ} 47^{\prime}-110^{\circ} 34^{\prime} \mathrm{E}$, 流域出口控制站为白家川水文站, 集水面积为 2.97 万 $\mathrm{km}^{2}$, 河道平 均比降 $1.8 \%$ 。流域气候属于温带大陆性干旱半干旱季风气候类型, 多年平均气温为 $8.9^{\circ} \mathrm{C}$, 多年平均降水量 为 $369.9 \mathrm{~mm}$,且降水量空间分布为自东南向西北递减,年内分布极其不均。

汉江是长江最大的支流,发源于秦岭南麓, 流经陕西和湖北,于武汉市汉口龙王庙汇人长江。汉江流域面 积 15.9 万 $\mathrm{km}^{2}$, 干流全长 $1577 \mathrm{~km}$, 通常分上、中、下游 3 段。丹江口以上为上游, 河长 $925 \mathrm{~km}$; 丹江口至钟祥 为中游, 河长 $270 \mathrm{~km}$; 钟祥以下为下游, 河长约 $382 \mathrm{~km}$ 。该流域位于北纬 $31^{\circ} 41^{\prime}-34^{\circ} 11^{\prime}$, 东经 $106^{\circ} 05^{\prime}-109^{\circ}$ $22^{\prime}$ 之间,本文选取安康站以上的汉江上游为研究区域,该区域全长 $426 \mathrm{~km}$, 集水面积 3.86 万 $\mathrm{km}^{2}$ 。流域气候 属于亚热带湿润性季风气候类型, 四季分明, 雨量充沛。流域多年平均气温为 $13.4^{\circ} \mathrm{C}$, 多年平均降水量 912.4 $\mathrm{mm}, 70 \%$ 左右的降水集中在 5-9 月。

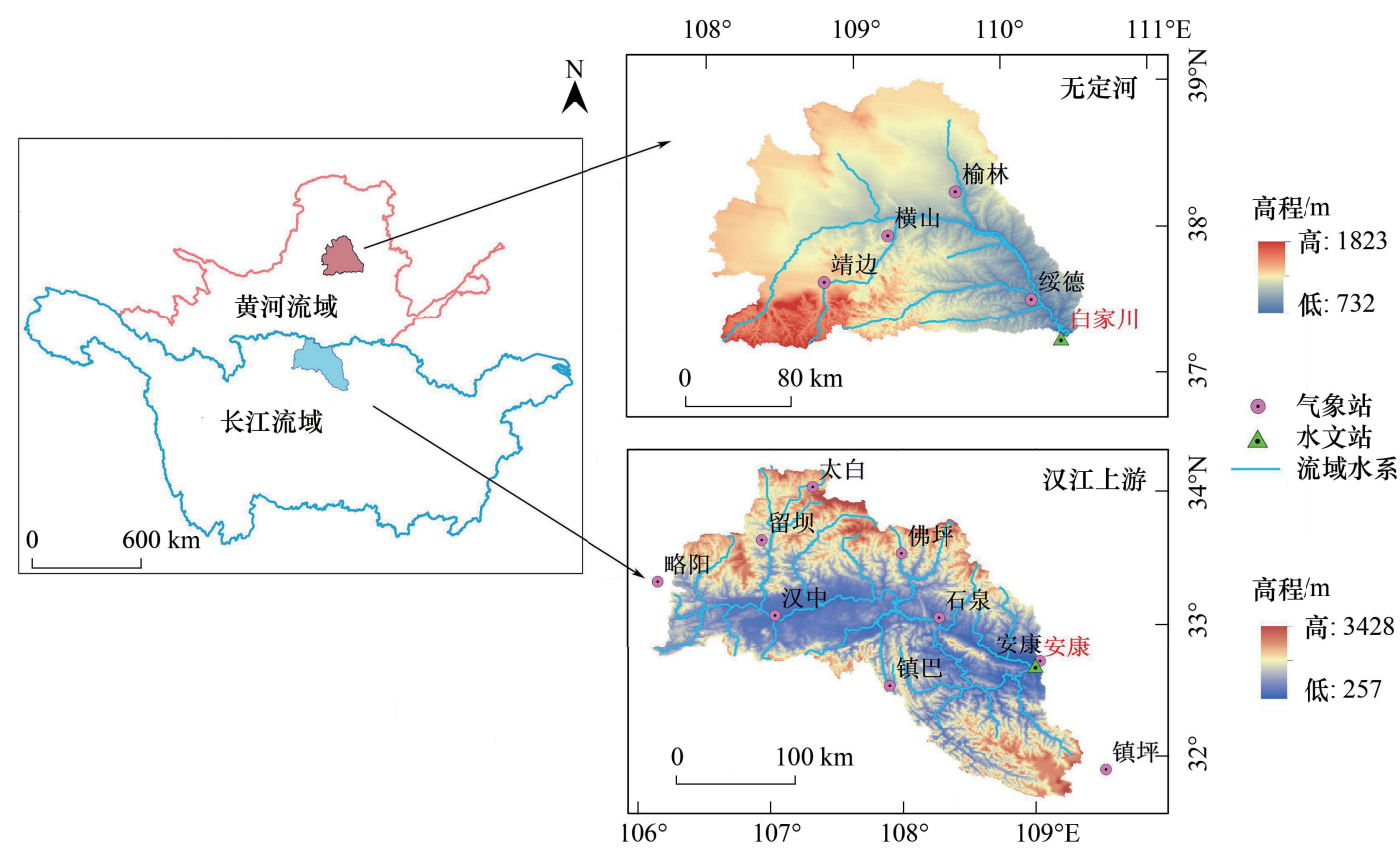

图 1 研究区地理位置

Fig.1 Location of the study area

\section{2 数据来源}

无定河流域 1970-2013 年白家川水文站的径流观测数据来源于黄河流域水文年鉴,气象数据来源于中 国气象科学数据共享服务平台 (http://data.cma.cn/) 提供的 4 个气象站 (榆林、横山、绥德、靖边) 的地面气候 数据集, 主要包括日降雨量 $(P)$ 、日平均气温 $(T)$ 、日最高气温 $\left(T_{\text {max }}\right)$ 、日最低气温 $\left(T_{\min }\right)$ 、相对湿度 $(R H)$ 、平 均风速 $\left(u_{2}\right)$ 以及日照时数 $(S)$ 资料。用 ArcGIS 10.2 软件中泰森多边形工具将点数据转换为面数据。

汉江上游径流控制站点安康水文站, 观测数据来源于长江流域水文年鉴; 选取流域内 9 个气象站点 (略 阳、留坝、太白、汉中、佛坪、石泉、镇巴、安康、镇坪), 并于中国气象科学数据共享服务平台获得 $P 、 T 、 T_{\text {max }}$ 、 
$T_{\mathrm{m} \text { in }} 、 R H 、 S$ 及 $u_{2}$ 资料,同样采用泰森多边形将其处理为面数据。

本研究使用的植被覆盖指数 (NDVI) 是由美国国家海洋大气局发布的 Global Inventory Modeling and Mapping Studies Normalized Difference Vegetation Index 3rd generation(GIMMS NDVI3g) 数据集,数据覆盖时段 为 1982-2015 年, 时间分辨率和空间分辨率分别为 $15 \mathrm{~d}$ 和 $0.083^{\circ} \times 0.083^{\circ}$ 。有效灌溉面积 $\left(\mathrm{EIA}, 1000 \mathrm{hm}^{2}\right)$ 来 源于农业部统计局官网。首先将下载的各省份数据除以该省行政区面积得到灌溉密度,再乘以研究流域在各 省的分布面积,最后将各省的计算结果求和,即得到研究流域的有效灌溉面积。

\section{2 研究方法}

2.1 潜在蒸散发的计算

目前用于估算潜在蒸散发 $\left(E T_{0}\right)$ 的方法主要有温度法、辐射法、质量传输法以及综合法 ${ }^{[17]}$ 。其中, Penman-Monteith (PM) 法因具有明确物理机制而被联合国粮农组织 (FAO) 推荐使用 ${ }^{[18]}$ 。本文采用考虑多种 气象要素,并经 Shuttleworth 于 1993 年修正的 PM 公式计算 $E T_{0}{ }^{[19]}$,具体公式如下:

$$
\lambda E T_{0}=\frac{\Delta}{\Delta+\gamma}\left(R_{n}-G\right)+\frac{\gamma}{\Delta+\gamma} 6.43\left(1+0.536 u_{2}\right)\left(\frac{100-R_{H}}{100}\right) e_{s}
$$

式中: $\lambda$ 为潜热 $(\mathrm{MJ} / \mathrm{kg}) ; \Delta$ 为饱和水汽压与温度关系曲线斜率 $\left(\mathrm{kPa} /{ }^{\circ} \mathrm{C}\right) ; \gamma$ 为干湿常数 $\left(\mathrm{kPa} /{ }^{\circ} \mathrm{C}\right) ; R_{n}$ 为净辐 射 $\left(\mathrm{MJ} \mathrm{m}^{-2} \mathrm{~d}^{-1}\right) ; G$ 为土壤热通量 $\left(\mathrm{MJ} \mathrm{m}^{-2} \mathrm{~d}^{-1}\right) ; u_{2}$ 为 $2 \mathrm{~m}$ 高处的风速 $(\mathrm{m} / \mathrm{s}) ; \mathrm{e}_{\mathrm{s}}$ 为空气饱和水汽压 $(\mathrm{kPa}) ; R_{H}$ 为 相对湿度 $(\%)$ 。

\section{2 基于 Budyko 框架计算参数 $n$}

Budyko 框架是指实际蒸散发 $(E)$ 受水分供应条件 (降水, $P$ ) 和能量供给条件 (潜在蒸散发, $E T_{0}$ ) 的共同 限制, 流域 $P$ 和 $E T_{0}$ 之间存在耦合平衡关系 ${ }^{[20]}$ 。其中, 经量纲分析和数学推导的傅抱璞公式可较好地反映流 域内的水热耦合状态, 故被广泛应用 ${ }^{[21]}$, 其公式为:

$$
\frac{E}{P}=1+\frac{E T_{0}}{P}-\left[1+\left(\frac{E T_{0}}{P}\right)^{n}\right]^{\frac{1}{n}}
$$

式中: $n$ 为流域水热耦合控制参数,受下垫面变化和气候变化的影响,决定着流域的水热分配。

公式(2)中 $E$ 可通过水量平衡公式计算,其表达式为:

$$
E=P-R-\Delta S
$$

式中: $E$ 为多年平均实际蒸散发量 $(\mathrm{mm}) ; R$ 为多年平均径流量 $(\mathrm{mm}) ; \Delta S$ 为流域蓄水变化量 $($ 在多年时间尺 度上,闭合流域近似为 $0^{[12,20]}$, 故可选取 $5 \mathrm{a}$ 作为滑动窗口使其为 0 来计算 $E$ )。

选取 $5 \mathrm{a}$ 为滑动窗口, 将滑动窗口内的 $P 、 E 、 E T_{0}$ 值作为输人数据, 即可根据最小二乘法拟合出一个 $n$ 值 来代表滑动窗口中间年份的水热耦合控制参数值 ${ }^{[3,20]}$ 。以此类推, 将所有窗口的 $n$ 值全部拟合, 即可得到流 域时变水热耦合控制参数序列。

2.3 Mann-Kendall 趋势检验法

Mann-Kendall 趋势检验简称 MK 检验, 是一种非参数检验方法。由于此方法适用性广、不受异常值干扰, 因而在水文、气象以及农业等领域被广泛应用。本研究采用 MK 法对水热耦合控制参数 $n$ 、气候要素和下垫 面因子进行趋势分析。MK 法通过统计量 $Z$ 来确定趋势, 当显著性水平为 0.05 时, 若 $|Z|>1.96$, 被观测序列 具有显著性变化趋势, $Z$ 值的正负表示观测序列呈上升或下降趋势, 具体计算公式见参考文献 ${ }^{[22-23]}$ 。

\section{4 逐步多元线性回归模型(SMLR)}

为确定气候和下垫面因子对时变流域水热耦合控制参数的影响, 本研究采用逐步多元回归模型 (Stepwise multiple linear regression model, SMLR) 建立时变参数 $n$ 与气候和下垫面因子的响应关系。首先建立一个包含 所有可能的因变量的模型, 然后将其逐步剔除, 在保持参数显著性的同时保持决定系数最高的模型, 即最后建 立“最优”方程的回归分析 ${ }^{[24]}$ 。该回归方法有效避免了自变量的多重共线性,使建立的模型更加可靠。 
选取气候要素 $\left(P 、 T 、 T_{\text {max }} 、 T_{\text {min }}, R H 、 S 、 u_{2}\right)$ 和下垫面因子 $($ NDVI 和 EIA $)$ 作为自变量, 时变参数 $n$ 作为因变 量, 进行逐步回归拟合方程:

$$
n=\alpha_{0}+\left(\alpha_{1} x_{c 1}+\cdots+\alpha_{k} x_{c k}\right)+\left(b_{1} x_{h 1}+\cdots+b_{k} x_{h k}\right)
$$

式中: $\alpha_{0}$ 为逐步回归方程的截距; $\alpha_{1}, \cdots, \alpha_{k}$ 及 $b_{1}, \cdots, b_{k}$ 为自变量的模型系数; $x_{c 1}, \cdots, x_{c k}$ 代表气候因子, $x_{h 1}$, $\cdots, x_{h k}$ 代表下垫面因子。最后将公式 (4) 计算得到的 $n$ 值作为模拟值, 将最小二乘法确定的 $n$ 值作为实际值, 并基于模拟值和实际值的确定性系数 $\left(R^{2}\right)$ 来确定 SMLR 模型的拟合效果。

\section{5 敏感性分析法}

不同气候区,时变水热耦合控制参数 $n$ 对气候因子和下垫面变化的响应不同。本文选用敏感性分析法来 估算干旱与湿润区流域气候和下垫面变化对时变参数 $n$ 的影响。假设时变参数 $n$ 对某影响因子 $x_{i}$ 的敏感性 系数为 $S_{x_{i}}$, 则 $S_{x_{i}}$ 为 $n$ 对该影响因子的偏导除以 $n$ 与该影响因子的比值,其计算公式为:

$$
S_{x_{i}}=\lim _{\Delta x_{i} \rightarrow 0}\left(\frac{\Delta n / n}{\Delta x_{i} / x_{i}}\right)=\frac{\partial n}{\partial x_{i}} \times \frac{x_{i}}{n}
$$

式中: $S_{x_{i}}$ 为时变参数 $n$ 对各影响因子 $\left(P 、 T 、 T_{\text {max }} 、 T_{\min } 、 R H 、 S 、 u_{2} 、 \mathrm{NDVI}\right.$ 和 EIA $)$ 的敏感性系数, 无量纲; $x_{i}$ 为影响 因子; $\frac{\partial n}{\partial x_{i}}$ 为参数 $n$ 对影响因子的偏导数。如 $S_{x_{i}}>0$, 则表明参数 $n$ 随着影响因子的增大而增大, 若 $S_{x_{i}}<0$, 则相 反。 $S_{x_{i}}$ 的绝对值越大, 则该影响因子对 $n$ 的影响越大。

\section{6 贡献率计算}

为定量评估各因子对参数 $n$ 变化的影响, 可将时变参数 $n$ 对影响因子的敏感性系数与研究时段内该因子 的相对变化率相乘, 即可得到该影响因子对 $n$ 变化的贡献率 ${ }^{[25-26]}$ 。具体计算公式如下所示:

$$
\begin{gathered}
C_{x_{i}}=S_{x_{i}} \times R_{x_{i}} \\
R_{x_{i}}=\frac{m \times T_{x_{i}}}{\overline{x_{i}}}
\end{gathered}
$$

式中: $C_{x_{i}}$ 为影响因子对参数 $n$ 变化的贡献率 $(\%) ; R_{x_{i}}$ 为影响因子的多年相对变化率; $m$ 为研究时段长度; $T_{x_{i}}$ 为 相应时段内影响因子的线性倾向率; $\overline{x_{i}}$ 为相应时段内影响因子的平均值。

所有影响因子对时变参数 $n$ 的贡献率之和则为气候因子和下垫面因子对参数 $n$ 变化的总贡献率。

\section{3 结果分析}

\section{1 影响因子的演变规律分析}

绘制研究区气候和下垫面因子在 1970-2013 年间的年际变化,如图 2 所示。对于干旱区的无定河流域, 径流 $R$ 呈下降趋势, 气候因子中 $P 、 E_{0} 、 R H 、 S$ 与 $u_{2}$ 在 1970-2013 年间均呈现下降趋势, 下垫面因子 NDVI 和 EIA 均呈上升趋势, 从图 2 中可以明显看出, 无定河降水呈下降趋势, 而近 50 年来气温呈上升趋势, 这使得流 域暖干化现象愈发加剧, 而无定河流域既是气候变化的敏感区, 又是环境脆弱区, 暖干化这一现象对该地区的 水资源可持续利用与工农业发展造成巨大威胁 ${ }^{[27]}$ 。对于湿润的汉江上游, 径流 $R$ 呈下降趋势, 气候因子中 $P 、 E_{0} 、 S$ 与 $u_{2}$ 在 1970-2013 年间均呈现下降趋势, 下垫面因子 NDVI 和 EIA 均呈上升趋势, EIA 从 1975 年开 始增长逐渐变缓。

采用 MK 法对无定河流域和汉江上游流域代表气候和下垫面因子的时间序列进行趋势检验,各因子的趋 势检验结果如表 1 所示。

由表 1 结果可知,对于干旱区的无定河流域, $R 、 E_{0} 、 u_{2}$ 通过了显著性水平为 0.05 的趋势检验, 呈现显著下 降趋势, $P 、 R H 、 S$ 呈不显著的下降趋势, $T 、 T_{\text {max }} 、 T_{\text {min }}$ 呈现显著的上升趋势,这与周园园等 ${ }^{[28-29]}$ 所得出的结论一 致;下垫面因子 NDVI 和 EIA 在 1970-2013 年呈明显的上升趋势, 这与 Hao 等 ${ }^{[30]}$ 得出的结果一致。对于湿 润区的汉江上游, $R$ 和 $u_{2}$ 呈现显著下降趋势, $P 、 E_{0}$ 和 $S$ 呈不显著的下降趋势, $T 、 T_{\text {max }} 、 T_{\text {min }}$ 均呈明显的上升趋 


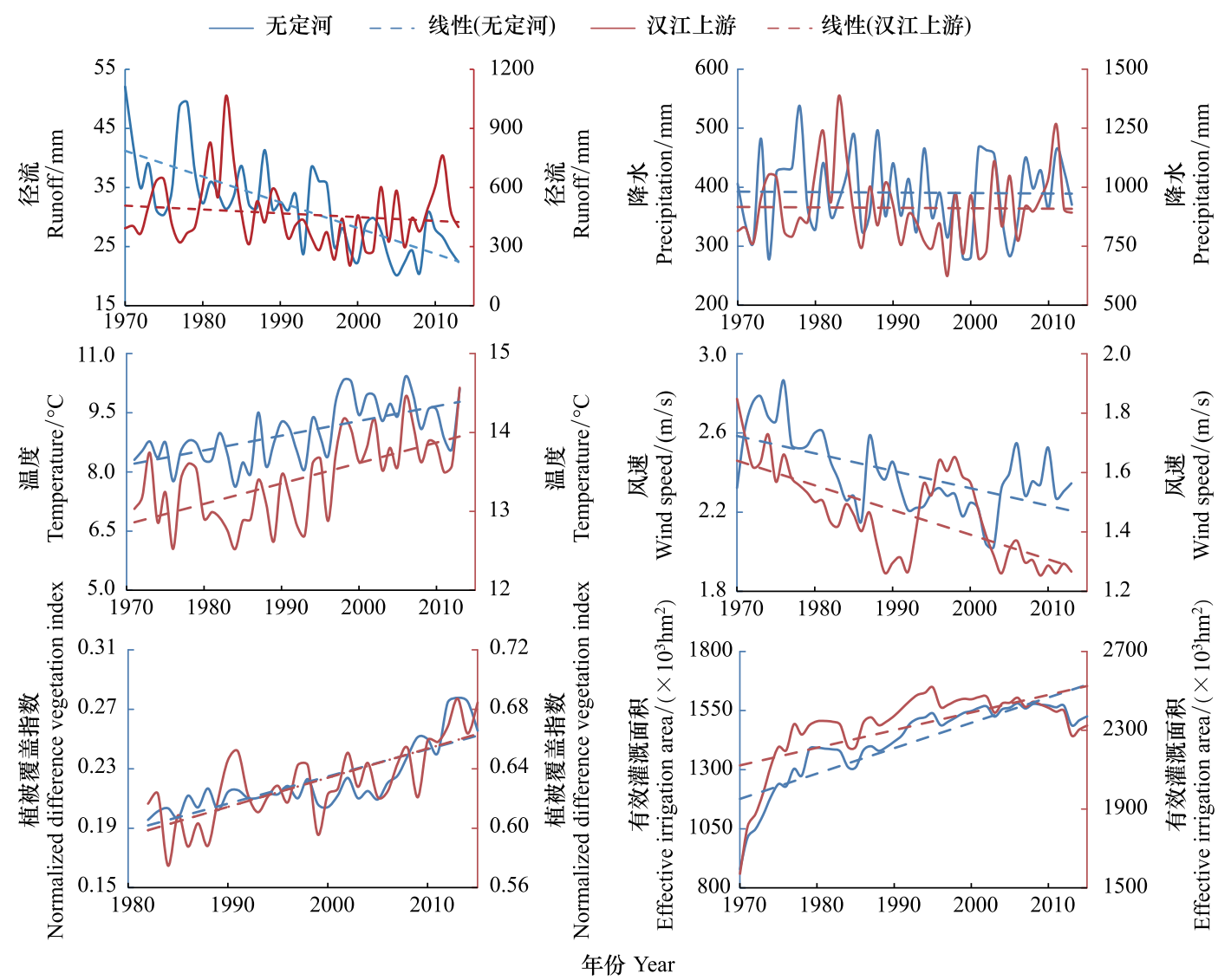

图 2 研究区气候和下垫面因子变化趋势示意图

Fig.2 Changes in climatic and underlying surface variables in the study area

势, 这与李紫妍 ${ }^{[32]}$ 所得出的结论一致。下垫面因子中 NDVI 和 EIA 均呈显著的上升趋势。EIA 从 1975 年开 始增长逐渐变缓。总体而言, 两流域的气温均呈显著上升趋势, 降水呈下降趋势, 说明所研究的干与湿流域都 存在暖干化现象。

表 1 MK 统计量 $Z$ 值结果表

Table 1 MK statistic $Z$ value result table

\begin{tabular}{|c|c|c|c|c|c|c|c|c|c|c|c|}
\hline 流域 Basin & $R$ & $P$ & $E_{0}$ & $T$ & $T_{\max }$ & $T_{\min }$ & $R H$ & $S$ & $u_{2}$ & NDVI & EIA \\
\hline 无定河 The Wuding River & $-5.43 *$ & -0.02 & $-2.74 *$ & $4.20^{*}$ & $3.41^{*}$ & $4.76^{*}$ & -1.79 & -1.81 & $-3.73 *$ & $5.25^{*}$ & $7.65 *$ \\
\hline $\begin{array}{l}\text { 汉江上游 } \\
\text { The upper Han River }\end{array}$ & $-2.04 *$ & -0.43 & -0.94 & $3.87^{*}$ & $3.15^{*}$ & $5.39^{*}$ & 1.06 & -1.55 & $-5.11^{*}$ & $4.65^{*}$ & $4.01 *$ \\
\hline
\end{tabular}

* 表示结果通过以显著性水平为 0.05 的趋势检验; $R$ : 径流 Runoff; $P$ : 降水 Precipitation; $E_{0}$ : 潜在蒸散发 Potential evapotranspiration; $T:$ 平均气温 Temperature; $T_{\text {max }}$ : 最高气温 maximum temperature; $T_{\text {min }}$ : 最低气温 minimum temperature; $R H$ : 相对湿度 relative humidity; $S$ : 日照时数 sunshine hours; $u_{2}:$ 风速 wind speed; NDVI: 植被覆盖指数 Normalized difference vegetation index;EIA : 有效灌溉面积 Effective irrigation area

\section{2 时变水热耦合参数的趋势分析}

基于水量平衡方程和傅抱璞公式,以 $11 \mathrm{a}$ 为滑动窗口来估算时变水热耦合参数 $n$,估算结果如图 3 所示。 由图 3 可知,干旱区无定河流域与湿润区汉江上游参数 $n$ 均呈现上升趋势。采用 MK 法对时变参数 $n$ 进行趋 势检验, 无定河和汉江上游的 $Z$ 统计量分别为 4.98 和 4.24 , 表明两流域水热耦合参数 $n$ 的上升趋势均显著。

干旱区无定河流域动态参数 $n$ 的变化范围为 $2.45-2.82$ 其值符合孙福宝等 ${ }^{[31]}$ 所给的参数范围, 且从 1996 年开始 $n$ 值持续上升, 最大值出现在 2008 年, 表明在干燥指数 $\left(E T_{0} / P\right)$ 保持不变时, 无定河流域自 1996 年以来蒸发率持续增加, 即在同一降水条件下, 随着无定河流域水热耦合状况不断变化, 流域的蒸发量持续增 

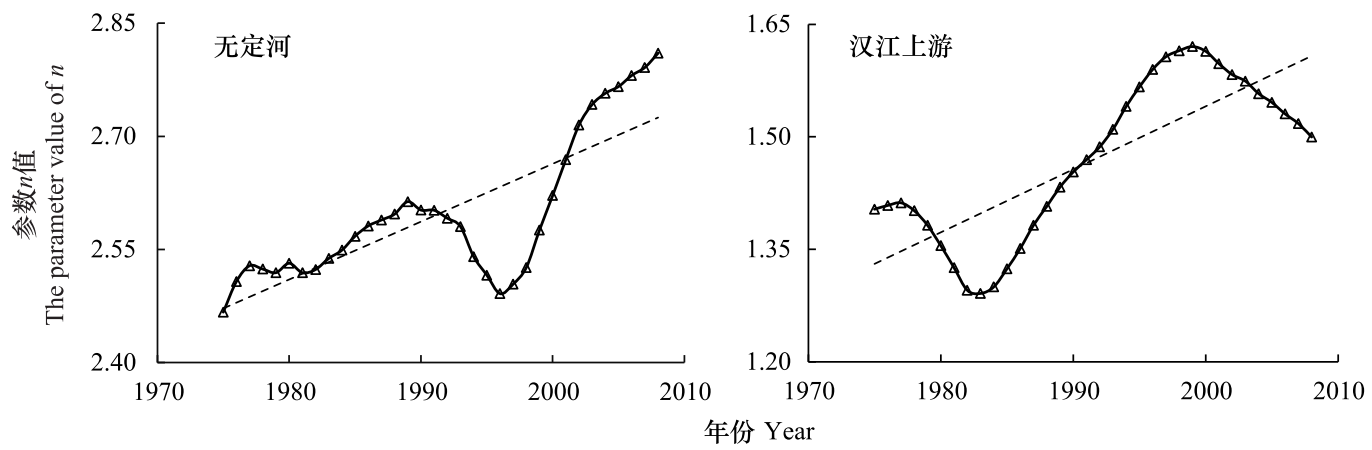

图 3 水热平衡参数的动态变化

Fig.3 The dynamic change of hydrothermal equilibrium parameter

大,而下垫面因子中 NDVI 在 1982-1999 年呈波动的缓慢增加趋势, 在 1999 年以后 NDVI 呈显著的增加趋 势, 说明 1999 年前该流域生态工程建设相对缓慢, 1999 年开始施行大规模退耕还林还草和水土保持等生态 修复工程,同时,随着灌溉面积的增加,共同驱动着径流量显著减小,流域干旱程度持续加剧。

湿润区汉江上游动态参数 $n$ 的变化范围为 $1.28-1.65$, 这与 $\mathrm{Li}$ 等 ${ }^{[3]}$ 的结果一致, 其中 $1983-1998$ 年参数 $n$ 持续增大, 自 1999 年以后,参数值明显减小。表明在相同降水条件下,汉江上游区域 1983-1998 年间蒸发 量增大, 流域干旱程度增强。自 1999 年以后, 流域蒸散发有减小的趋势, 流域干旱程度有所缓解, 主要是由于 1999 年以后汉江上游地区 EIA 呈显著下降趋势, 径流有增加的趋势。

3.3 水热耦合参数变化的归因分析

3.3.1 时变参数 $n$ 对影响因子的响应关系

为进一步研究参数 $n$ 对各影响因子的响应, 采用 SMLR 模型来拟合参数 $n$ 和气候因子 $\left(P 、 T 、 T_{\text {max }} 、 T_{\text {min }}\right.$ 、 $\left.S 、 u_{2} 、 R H\right)$ 及下垫面因子 (NDVI、EIA) 的关系式。在逐步回归的过程中,已剔除与参数 $n$ 变化相关性弱的影响 因子,保留了与时变参数密切相关的因子。模拟结果如下:

$$
\begin{array}{ll}
\text { 无定河: } & n_{1}=2.238+0.0476 P+0.1127 T+0.0577 u_{2}+1.8212 \mathrm{NDVI} \\
\text { 汉江上游: } & n_{2}=2.266-0.0403 P+0.0474 T-1.218 \mathrm{NDVI}+0.0351 \mathrm{EIA}
\end{array}
$$

由式 (8) 可知,对干旱区无定河流域来说, $P 、 T 、 u_{2}$ 和 NDVI 对水热耦合参数 $n$ 的变化具有显著意义; 由式 (9) 可知,对湿润区汉江上游来说, $P 、 T 、 \mathrm{NDVI}$ 和 EIA 与水热耦合参数 $n$ 的变化最为相关。表明气候因素和下 垫面因素共同影响着无定河流域和汉江上游水热耦合参数。此外,将干旱区和湿润区影响因子的实测值代人 公式 (8) 和 (9), 计算参数 $n$ 的模拟值, 并将其和参数 $n$ 的实测值进行对比,结果如图 3 所示。SMLR 模型对干 旱区和湿润区流域参数 $n$ 拟合的确定性系数 $R^{2}$ 分别为 0.85 和 0.98 ,说明 SMLR 模型的模拟效果较好。

3.3.2 参数 $n$ 对影响因子的敏感性分析

采用敏感性系数法进一步分析参数 $n$ 对影响因子的敏感程度,结果如表 2 所示。

表 2 驱动因子对参数 $n$ 变化的敏感性系数

Table 2 The sensitivity of drivering factor to the change of parameter $n$

\begin{tabular}{lcc||lcc}
\hline $\begin{array}{l}\text { 研究区域 } \\
\text { Study area }\end{array}$ & $\begin{array}{c}\text { 要素 } \\
\text { Factors }\end{array}$ & $\begin{array}{c}\text { 敏感性系数 } S \\
\text { Sensitive coefficient }\end{array}$ & $\begin{array}{l}\text { 研究区域 } \\
\text { Study area }\end{array}$ & $\begin{array}{c}\text { 要素 } \\
\text { Factors }\end{array}$ & $\begin{array}{c}\text { 敏感性系数 } S \\
\text { Sensitive coefficient }\end{array}$ \\
\hline 无定河 & $P$ & 0.485 & 汉江上游 & $P$ & 0.125 \\
The Wuding River & $T$ & 0.456 & The upper Han River & $T$ & 0.501 \\
& $u_{2}$ & -0.098 & & EIA & 0.340 \\
& NDVI & 0.247 & & NDVI & -0.505 \\
\hline
\end{tabular}




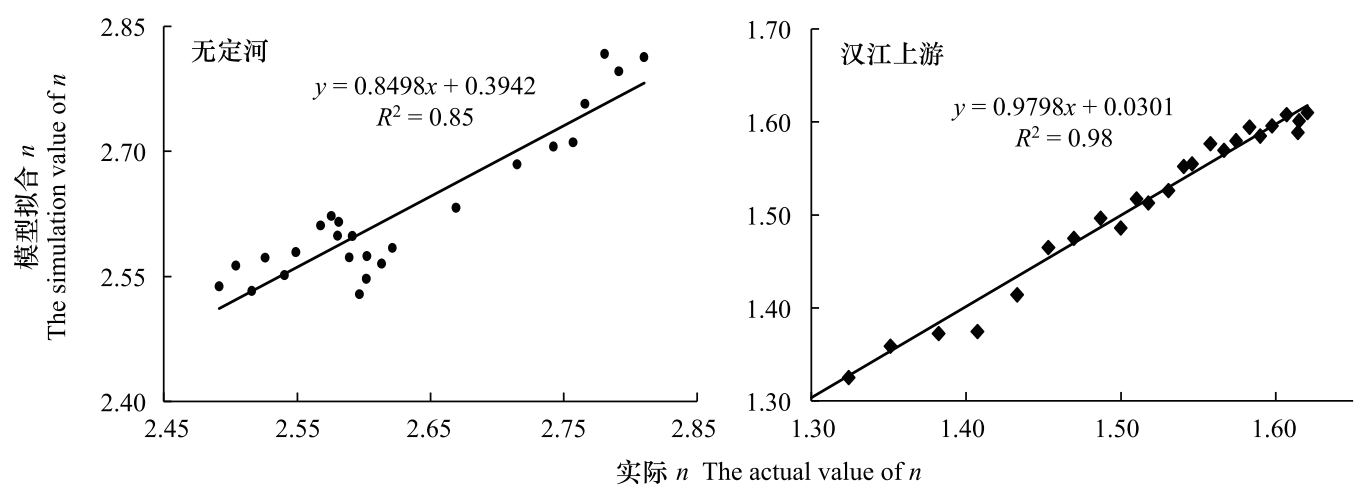

图 4 参数 $n$ 实际值与模拟值的比较

Fig.4 The comparison between the actual value of parameter $n$ and the simulated value of parameter $n_{0}$

对干旱区无定河流域,参数 $n$ 对 $P$ 的敏感系数最大, 为 0.485 , 对 $T$ 和 NDVI 的敏感系数次之, 对 $u_{2}$ 的敏感 系数最小。表明在各影响因子的变化量相同时, 无定河流域水热耦合参数 $n$ 对降水变化的响应最为强烈, 对 气温和 NDVI 次之, 对风速的响应最弱, 且风速对参数 $n$ 的变化有负向影响。因为作为水量限制型区域 $\left(E_{0} / P>1\right)$, 无定河降水的变化会直接影响该区域的水热状况, 而温度的变化会直接影响潜在蒸散发,进而间 接影响流域的水热状况。

对湿润区汉江上游,参数 $n$ 对 NDVI 和 $T$ 的敏感系数最大,对 EIA 和 $P$ 的敏感系数次之。表明汉江上游 水热耦合参数对植被覆盖度和日平均气温变化的响应较为强烈,对有效灌溉面积和降水变化的响应次之。其 中,植被覆盖度的改变对参数 $n$ 的变化有负向影响。总体来说,干旱区流域与湿润区流域的时变水热耦合参 数对气候和下垫面变化的敏感程度不同。

3.3.3 影响因子对参数 $n$ 变化的贡献率

为了进一步定量评估气候变化和下垫面条件的改变对参数 $n$ 变化的影响,基于研究区域 SMLR 模型的结 果,计算气候因子和下垫面因子对水热耦合参数变化的贡献率,结果如表 3 和图 4 所示。

表 3 驱动因子对参数 $n$ 变化的贡献率

Table 3 Contributions of driving factor to parameter $n$ changes

\begin{tabular}{lccccc}
\hline & \multicolumn{5}{c}{ 贡献率 Contribution rate/\% } \\
\cline { 2 - 6 } 研究区域 & $\begin{array}{c}\text { 降水 } P \\
\text { Precipitation area }\end{array}$ & $\begin{array}{c}\text { 平均气温 } T \\
\text { Temperature }\end{array}$ & $\begin{array}{c}\text { 风速 } u_{2} \\
\text { Wind speed }\end{array}$ & $\begin{array}{c}\text { 植被覆盖指数 NDVI } \\
\text { Normalized difference } \\
\text { vegetation index }\end{array}$ & $\begin{array}{c}\text { 有效灌溉面积 EIA } \\
\text { Effective irrigation } \\
\text { area }\end{array}$ \\
\hline 无定河 The Wuding River & -54.7 & 29.5 & 35.7 & 89.5 & \\
汉江上游 The upper Han River & 31.3 & 14.4 & & -28.8 & 83.1 \\
\hline
\end{tabular}

在干旱区无定河流域, $P$ 对水热耦合参数 $n$ 的贡献率为 $-54.7 \%, T 、 u_{2}$ 和 NDVI 对参数 $n$ 的贡献率分别为 $29.5 \% 、 35.7 \%$ 和 $89.5 \%$, 表明 $P$ 对水热耦合参数的增加具有负向驱动作用,而 $T 、 u_{2}$ 和 NDVI 的改变对参数的 增加具有正向驱动作用。由于降水对参数增加的负向驱动作用小于气温、风速和植被覆盖度的正向驱动作 用, 故参数呈现增加趋势。其中, NDVI 对参数增加的贡献率最大, 表明植被覆盖是引起干旱区无定河流域水 热耦合参数增加的主导因子。总体来说, 气候因素对干旱区无定河流域参数 $n$ 变化的贡献率为 $10.5 \%$, 而下 垫面条件的贡献率为 $89.5 \%$,故下垫面条件的改变主导着干旱区无定河流域水热耦合参数的变化。自 1999 年黄土高原施行退耕还林 (草) 生态修复措施以来, 黄河流域逐年变绿 ${ }^{[32]}$ 。无定河位于黄土高原西北部地 区, 同样存在变绿的趋势。无定河作为水量限制型区域 $\left(E_{0} / P>1\right)$, 大规模的植树造林会通过蒸腾消耗大量的 水资源, 会对流域水文循环过程产生强烈干扰作用, 进一步改变流域水热状况, 导致水热耦合参数 $n$ 的变化, 从而使流域径流减少。因此,植被覆盖度的增加是无定河流域水热状况变化的主导因素。 
在湿润区汉江上游, $P 、 T 、 \mathrm{NDVI}$ 和 EIA 对参数 $n$ 变 化的贡献率分别为 $31.3 \% 、 14.4 \% 、-28.8 \%$ 和 $83.1 \%$, 其 中, P、T 和 EIA 的变化对参数 $n$ 的增加具有促进作用, 而 NDVI 的变化对参数 $n$ 的增加具有抑制作用。由于 降水、气温和有效灌溉面积对参数增加的正向驱动作用 大于植被覆盖度的负向驱动作用, 故参数在 19702013 年间呈现增加趋势。从贡献率的数值大小来看, 有效灌溉面积是湿润区流域参数 $n$ 变化的主导因子。 总体来看,气候因素对湿润区水热耦合参数 $n$ 变化的贡 献率为 $45.7 \%$, 而下垫面因子的贡献率为 $54.3 \%$ 。因为 汉江上游是能量限制型区域 $\left(E_{0} / P<1\right)$, 该区域的植被 变绿并未消耗大量的水资源, 故植被覆盖的增加并非导 致汉江上游流域水热耦合参数变化的主要因素。此外, 汉江上游流域为陕南的“粮仓”, 是重要的农业基地, 有 效灌溉面积较大 ${ }^{[3]}$ 。经贡献率计算结果可知, 有效灌

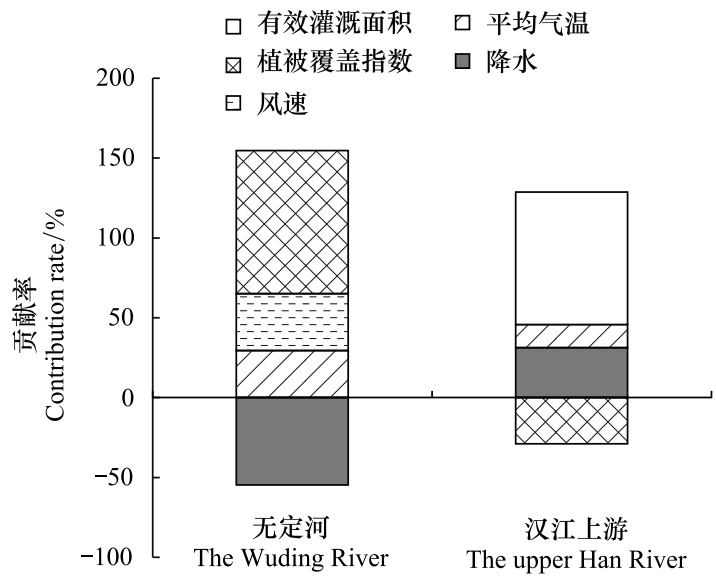

图 5 气候和下垫面因子对参数 $n$ 变化的贡献率

Fig.5 Contributions of climatic and underlying surface characteristic factors to parameter $\boldsymbol{n}$ changes 溉面积主导着该地区水热耦合参数的变化。

综上所述, 不同气候带的异同主要体现在干燥度指数 $\left(E_{0} / P\right)$, 干旱区无定河流域和湿润区汉江上游水热 状况不同,故主导其水热耦合参数变化的因子也不同。

\section{4 结论}

本文选取干旱区无定河流域与湿润区汉江上游为研究区域,基于 Budyko 框架,采用 MK 趋势检验、SMLR 模型、敏感性系数法等, 对不同水热条件下,水热耦合参数演变规律及影响因素进行了分析,并定量评估了干 旱区流域与湿润区流域气候与下垫面条件的改变对水热耦合参数变化的贡献程度,主要结论如下:

(1) 在 1970-2013 年间,两流域水热耦合参数整体呈显著上升趋势, 蒸发量增加而径流量下降, 流域干 旱程度总体呈加剧状态。而对汉江上游而言, 自 1999 年以后,有效灌溉面积显著减少, 蒸发量减少而径流量 增加, 其水热耦合参数出现下降趋势。

(2) 影响干旱流域与湿润流域水热平衡参数 $n$ 的敏感性因子不同。无定河参数 $n$ 对降水变化具有较高 的敏感性,对风速的敏感性最弱; 汉江上游参数 $n$ 对 NDVI 和气温变化均较为敏感。

(3) 对于水量限制型流域 (无定河), 植树造林通过蒸腾消耗大量的水资源, 导致降水在蒸发、下渗及径流 之间的分配发生改变。故植被覆盖度的增加主导着无定河流域水热耦合状况的变化,其贡献率为 $89.5 \%$; 对 于能量限制型流域 (汉江上游), 有效灌溉面积的增加主导着该流域水热耦合状况的变化, 其贡献率为 $83.1 \%$ 。

本研究对比分析了不同气候区气候和下垫面条件变化对流域水热耦合状况的影响,研究结果有助于揭示

变化环境下流域水文循环的演变规律。此外,本研究采用的流域水热耦合平衡动态变化的驱动力分析框 架可以推广至其他流域。由于数据的限制, 本研究在人类活动因子的选取上还不全面, 由于下垫面变化对水 热平衡参数变化的影响较为复杂, 接下来的研究中会进一步考虑土壤湿度、基流以及遥相关因子 (太阳黑子、 厄尔尼诺南方涛动等) 对流域水热耦合状况的影响。

参考文献 (References) :

[ 1 ] Trabucco A, Zomer R J, Bossio D A, van Straaten O, Verchot L V. Climate change mitigation through afforestation/reforestation: a global analysis of hydrologic impacts with four case studies. Agriculture, Ecosystems \& Environment, 2008, 126(1/2): 81-97.

[2 ] 董国强, 杨志勇, 于赢东. 下垫面变化对流域产汇流影响研究进展. 南水北调与水利科技, 2013, 11(3): 111-117, 126-126. 
[ 3 ] Li Z Y, Huang S Z, Liu D F, Leng G Y, Zhou S, Huang Q. Assessing the effects of climate change and human activities on runoff variations from a seasonal perspective. Stochastic Environmental Research and Risk Assessment, 2020, 34(3/4) : 575-592.

[ 4 ] Liu Y, Fu B J, Lü Y H, Wang Z, Gao G Y. Hydrological responses and soil erosion potential of abandoned cropland in the Loess Plateau, China. Geomorphology, 2012, 138(1): 404-414.

[ 5 ] Wang C, Wang S, Fu B J, Lü Y H, Liu Y X, Wu X. Integrating vegetation suitability in sustainable revegetation for the Loess Plateau, China. Science of the Total Environment, 2021, 759: 143572.

[ 6 ] Feng X M, Fu B J, Piao S L, Wang S, Ciais P, Zeng Z Z, Lü Y H, Zeng Y, Li Y, Jiang X H, Wu B F. Revegetation in China's Loess Plateau is approaching sustainable water resource limits. Nature Climate Change, 2016, 6(11): 1019-1022.

[ 7 ] Li C B, Wang W M, Wang W R, Qi J G, Yang L S, Zhang Y, Wu L, Cui X, Wang P. An analytical approach to separate climate and human contributions to basin streamflow variability. Journal of Hydrology, 2018, 559: 30- 42.

[ 8 ] Teng J, Chiew F H S, Vaze J, Marvanek S, Kirono D G C. Estimation of climate change impact on mean annual runoff across continental Australia using Budyko and Fu equations and hydrological models. Journal of Hydrometeorology, 2012, 13(3) : $1094-1106$.

[9] 徐宗学, 赵捷. 生态水文模型开发和应用一一回顾与展望. 水利学报, 2016, 47(3): 346-354.

[10] Guo A J, Chang J X, Wang Y M, Huang Q, Guo Z H, Li Y Y. Uncertainty analysis of water availability assessment through the Budyko framework. Journal of Hydrology, 2019, 576: 396-407.

[11] Zhao J, Huang S Z, Huang Q, Wang H, Leng G Y. Detecting the dominant cause of streamflow decline in the loess plateau of China based on the latest Budyko equation. Water, 2018, 10(9): 1277.

[12] Patterson L A, Lutz B, Doyle M W. Climate and direct human contributions to changes in mean annual streamflow in the South Atlantic, USA. Water Resources Research, 2013, 49(11): 7278-7291.

[13] Xu X Y, Yang D W, Yang H B, Lei H M. Attribution analysis based on the Budyko hypothesis for detecting the dominant cause of runoff decline in Haihe basin. Journal of Hydrology, 2014, 510: 530-540.

[14] Huang S Z, Chang J X, Huang Q, Chen Y T, Leng G Y. Quantifying the relative contribution of climate and human impacts on runoff change based on the Budyko hypothesis and SVM model. Water Resources Management, 2016, 30(7) : 2377-2390.

[15] 杨大文, 张树否, 徐翔宇. 基于水热耦合平衡方程的黄河流域径流变化归因分析. 中国科学: 技术科学, 2015, 45(10): 1024-1034.

[16] 张丽梅, 赵广举, 穆兴民, 高鹏, 孙文义. 基于 Budyko 假设的渭河径流变化归因识别. 生态学报, 2018, 38(21): 7607-7617.

[17] 伍海, 夏军, 赵玲玲, 宋进喜, 李天生. 变化环境下 12 种潜在蒸散发估算方法在中国不同干湿区的适用性. 南水北调与水利科技 (中英 文), 2021,19(1):01-11.

[18] Allen R G, Pereira L S, Raes D, Smith M, Allen R G, Pereira L S, Raes D, Smith M A. Crop Evapotranspiration-Guidelines for Computing Crop Water Requirements. Rome, Italy: FAO, 1998.

[19] Xing W Q, Wang W G, Shao Q X, Yong B. Identification of dominant interactions between climatic seasonality, catchment characteristics and agricultural activities on Budyko-type equation parameter estimation. Journal of Hydrology, 2018, 556: 585-599.

[20] Zhao J, Huang S Z, Huang Q, Leng G Y, Wang H, Li P. Watershed water-energy balance dynamics and their association with diverse influencing factors at multiple time scales. Science of the Total Environment, 2020, 711: 135189.

[21] 傅抱璞. 论陆面蒸发的计算. 大气科学, 1981, 5(1): 23-31.

[22] 李天生, 夏军. 基于 Budyko 理论分析珠江流域中上游地区气候与植被变化对径流的影响. 地球科学进展, 2018, 33(12): 1248-1258.

[23] Kendall M G. Rank Correlation Methods. 2nd ed. London: Charles Griffin, 1955.

[24] Zare S, Shamsi S R F, Abtahi S A. Weakly-coupled geo-statistical mapping of soil salinity to Stepwise Multiple Linear Regression of MODIS spectral image products. Journal of African Earth Sciences, 2019, 152: 101-114.

[25] Yin Y H, Wu S H, Chen G, Dai E F. Attribution analyses of potential evapotranspiration changes in china since the 1960s. Theoretical and Applied Climatology, 2010, 101(1/2): 19-28.

[26] 安涁, 肖薇薇. 汉江上游流域潜在蒸散量敏感性分析. 水资源保护, 2019, 35(5): 59-65.

[27］李志, 赵西宁. 1961-2009 年黄土高原气象要素的时空变化分析. 自然资源学报, 2013, 28(2): 287-299.

[28] 周园园, 师长兴, 杜俊, 范小黎. 无定河流域 1956-2009 年径流量变化及其影响因素. 自然资源学报, 2012, 27(5) : 856-865.

[29] Tian X J, Zhao G J, Mu X M, Zhang P F, Tian P, Gao P, Sun W Y. Hydrologic alteration and possible underlying causes in the Wuding River, China. Science of the Total Environment, 2019, 693: 133556.

[30] Hao J Q, Gao J E, Luo H. Changes and implications of the relationship between rainfall, runoff and sediment load in the Wuding River basin on the Chinese Loess Plateau. CATENA, 2019, 175: 228-235.

[31』孙福宝,杨大文, 刘志雨,众振涛. 基于 Budyko 假设的黄河流域水热耦合平衡规律研究. 水利学报,2007,38(4): 409-416.

[32] 李紫妍. 汉江上游水文气象时空变异和水文模拟的不确定性评估 [D]. 西安: 西安理工大学, 2019. 